\title{
Hiring a professional medical writer: is it equivalent to ghostwriting?
}

\author{
Natasha Das ${ }^{* 1}$, Saurendra Das² \\ ${ }^{1}$ Freelance Medical Writer, Delhi, India \\ 2Excel Life Sciences, NOIDA, India \\ *Corresponding author: drnatashadas@gmail.com
}

\begin{abstract}
Authors of articles published in medical journals are often busy researchers who cannot afford time devoted to writing. Though they are experts in their own therapeutic area, more often than not, researchers find it difficult to actually write and publish their research. Professional medical writers with their expertise in writing clear, concise, comprehensible, and coherent content are often a great support to researchers. Their contribution to the manuscript is usually focused on getting a manuscript ready for publication. They are not authors unless they make substantial contribution to the study according to the guidelines of the International Committee of Medical Journal Editors (ICMJE). However, medical writing is not the same as ghostwriting. Ghostwriting is unethical. Medical writers can be legitimate contributors to the medical manuscript. Several international guidelines including the ICMJE guidelines require authors to acknowledge the contribution of medical writers in the published article. Medical writers whose name is publicly associated with the article in turn make an extra effort to ensure that all applicable publication ethics and style guidelines are adhered to. This article discusses the current international guidelines about the acknowledgement of writing assistance. It also emphasizes on how acknowledging medical writing support can go a long way in curbing the menace of scientific misconduct including ghostwriting.
\end{abstract}

Key words: medical writer; ghostwriter; authorship; ethics in publishing; acknowledgement

\section{Introduction}

Medical authors try to communicate the results of their research, clinical practice or thinking to their colleagues by writing about it in medical journals. Generally, they are amateurs in the field of writing. Not all amateurs do a poor job when writing for medical journals. Yet, professional medical writers are more likely to do a better job since that is their forte. Specialization always helps. Medical writers specialize in writing for the medical domain.

Way back in 1963, McVeagh had suggested making the medical writer a member of the research team in such a way that the medical writer's responsibility is "the presentation of the researcher's results" (1). However, several questions need to be answered before thinking of hiring a professional medical writer.

- Is it not necessary that the researcher should write his own paper?

- Clinical practice and lives of patients depend on what is published in medical journals. Is it not necessary that the paper should be written by an expert in the therapeutic area? Are professional medical writers also therapeutic area experts?

- How does a professional writer improve the quality of the paper? 
- Should the writer be included as an author of the paper? Who should be included as authors?

- Will not including the writer as an author because he has not contributed substantially to the research, amount to ghostwriting?

- Is there an ethical method by which the expertise of a medical writer can be used in order to enhance the chances of acceptance of the manuscript?

This paper attempts to answer such queries regarding professional medical writers. In this paper, we try to explore the role of professional writers in the medical publication process. We also try to find out if there is an ethical method of using the expertise of a medical writer without being accused of promoting ghostwriting.

\section{Writing your own papers}

For a researcher, there is possibly nothing as perfect as writing and publishing his own research results. Nobody understands the research and its results as clearly as those who did the research. Yet many physicians do not publish a single paper in their lifetime. There are many who publish a couple of papers but do not publish all of their research. They have a lot to report but end up reporting only a few cases or studies.

\section{What impedes publishing in a medical journal?}

Many physicians do not write a paper simply because they believe their research is not worthy of publication. Unless the results are published, the research remains incomplete. All research needs to be published. Many physicians, at least in the developing countries, are overloaded with clinical work and have very little time to write their own papers and publish them. They cannot afford time that is devoted to writing. Some others are unaware of how to choose the right journal and how to carry out the entire process of publishing an article. In situations such as these, hiring a writer comes in handy.

\section{Experts in their own fields}

Does it help if the medical writer is a therapeutic area expert? Yes, in many cases, it does. Is it necessary for the medical writer to be an expert in the therapeutic area? No.

The responsibility of the content of the published article lies on the authors. The authors are experts in their therapeutic area. Medical writers are experts in their own field, i.e., writing. They help in making the communication timely and compliant with universally accepted standards or according to the specific style that the targeted journal follows.

The international competency model for medical writers does not suggest therapeutic area expertise as a requirement $(2,3)$. Instead, it lists several other competencies for being an effective science communicator, e.g., knowledge of publication and style guidelines, knowledge of publication ethics, language and grammar skills, computer skills, project management skills, etc.

Professional medical writers come from diverse backgrounds. They usually have advanced degrees in life sciences and many may even be physicians, dentists, nurses, pharmacists and PhDs. They combine their understanding of science with an ability to communicate the message clearly through their writing skills.

The medical writer integrates inputs, expertise and opinions of the authoring team into the document and communicates the information in such a way that it satisfies the readers' needs (3). Sometimes, it may be advantageous if the writer is a non-expert in the concerned therapeutic area. A therapeutic area expert may subconsciously leave gaps in the writing because he may feel others will understand the content as well as he does. As a result, the content may not be clear and logically presented.

\section{How a professional writer helps}

Because of the interdisciplinary nature of medicine and the wide access to journal articles, articles on a highly technical topic may ultimately be read by 
experts in the niche field as well as by people from other disciplines. For example, an article about a clinical trial on the use of ruboxistaurin mesylate in diabetic retinopathy may be read by clinical research professionals, endocrinologists, ophthalmologists, pharmocologists as well as general physicians. Today, even patients and their caretakers reach out to articles published in medical journals to enhance their understanding of the health conditions, the treatment options available and the potential complications of the disease or the therapy. The professional writer is at times a nonexpert in the therapeutic area. Yet, he or she understands the need for the content to be concise, comprehensible, clear and coherent (the four Cs for an effective communication). The medical writer, through his or her expertise in writing, adds logic and flow and improves the style of writing making high end research articles comprehensible to the reader. A good professional writer identifies and fills any gaps in clarity and flow. This ensures that the end product is a clearly written manuscript with no ambiguity in the content. If a document lacks in clarity, the actual thought that the authors want to communicate may be lost $(4,5)$.

Each year, reviewers and editors return several manuscripts for revision or even reject them because of poor writing styles, poor organization of the content and even poor English and grammar $(6,7)$. The writers organize the author's thoughts in such a way that the sentences and paragraphs are connected to each other in a logical sequence. They help putting medical jargon into plain, reader-friendly language so that the readership is increased. Professional medical writers are aware of and adhere to ethical publication practices. They ensure that all relevant guidelines and style formats are followed. This reduces the number of review cycles and enhances chances of acceptance and publication.

\section{The authorship dilemma}

Considering the amount of contribution medical writers make to the preparation of the draft and even of the final manuscript, should they be listed as coauthors?
It is not mandatory to include medical writers as authors as they may not make substantial intellectual contribution to the article. According to the International Committee of Medical Journal Editors (ICMJE) Guidelines, an author apart from contributing to the preparation of the manuscript, also contributes to the concept and design of the study as well as to the data acquisition and/or analysis (8). Even the European Medical Writers Association (EMWA) insists in the guidelines for its members that medical writers who do not qualify the authorship criteria of a target journal should not agree to be listed as authors (9). EMWA guidelines point out that "professional writers are unlikely to be named as authors on primary research articles". However, in case of review article, writers may qualify as authors if they have done an extensive literature search (9). Only those who agree to take public responsibility of the content should become authors $(8,9)$.

The interaction between the professional writers and the authors can be clearly defined using the GATE principles (10). Do the authors agree to Guarantee the article? Did they Advise the writer before as well as after starting the assignment? Is there Transparency about the contribution of a professional writer? Does the writer have sufficient Expertise or knowledge about the field or topic?

Most journal policies recommend that professional medical writers whose contribution to a manuscript qualifies them as authors according to the ICMJE criteria should be listed as authors. If their contribution does not qualify them to be authors, they should be adequately acknowledged in the Acknowledgement or the Contributors sections $(11,12)$.

In countries where hierarchy plays a significant role in professional life, some physicians seek supportive assistance from their subordinates to undertake the entire process of publishing their own data. Any writing assistance of this nature should also go into the Acknowledgement section.

\section{How the medical writers work along with the named authors}

The named authors are responsible for all stages of the publication. In studies involving many inves- 
tigators, the sponsoring company is encouraged to identify a 'writing group' or the named authors who collaborate with the professional writer in developing the manuscript for publication (9). The publication outline and the key message are first approved by the named authors and then the writer gets down to the detailed process of writing. Thus, the writer facilitates the writing of the manuscript while the named authors are responsible for its content.

\section{'Medical writers', 'ghostwriters' and 'honorary authors'}

It is a myth that medical writing is the same as ghostwriting. It is not the same. When the people who write the article are not acknowledged as authors or otherwise in the published version of the article, they are called 'ghostwriters'. They remain as 'ghosts', invisible to the reader.

There are marginal differences between the terms 'guest authors' and 'gift authors'. These are included under a broader term called 'honorary authors' (13). By and large, this term includes all those who are mentioned as authors, despite minor or negligible contributions, if any. Ghostwriters are 'unnamed writers' of the article while honorary authors are named authors who make negligible or no contribution to the article. Both ghostwriting and honorary authorship are considered unethical practices.

What is unethical about honorary authorship? The honorary authors do not fulfil the ICMJE criteria for authorship. They may, in some cases, review the draft of the manuscript, make suggestions for improvement, and approve the final version of the manuscript. Yet, this contribution does not qualify them as authors according to the ICMJE criteria. They ought to have made significant contribution to the concept and design of the study and data collection and/or analysis, in addition to reviewing an important draft and approving the final version of the manuscript (14).

Why is ghostwriting considered unethical? Ghostwriters can at times be biased. An explicitly biased article can be harmful to the patients when clinical decision making is based on the article. Even when not biased, ghostwriting puts all the public blame of the writing on the authors. This hampers the public trust in the pharmaceutical industry as well as the medical profession. Most journals insist on saying 'no' to ghostwriting.

Since ghostwriting is not declared, there is a high chance that many of the articles published in journals are still being ghostwritten, a practice that is widely viewed as dishonest, unethical and unacceptable.

This dishonesty can be curbed by encouraging authors to declare any writing support sought. Professional medical writers are legitimate contributors to the article $(15,16)$. They are a blessing while ghostwriters are a curse (17).

\section{Legitimate contributors to manuscripts}

By declaring the medical writing help they receive, authors save their own skins. Their article is not accused of being ghostwritten. Writers whose names are disclosed, in turn, are accountable for what they write and hence, ensure all steps are taken to avoid possible misconduct. A retrospective systematic study of retracted publications showed that publications retracted because of misconduct rather than mistakes rarely involved declared medical writers (18). Undisclosed medical writers, based on the fact that their name is never associated with the published article and they have no real or implied public responsibility of what goes into the article, may possibly be less ethically minded than the disclosed medical writers.

Several guidelines today encourage transparency about the use of professional medical writers.

The ICMJE guideline says (15): "All contributors who do not meet the criteria for authorship should be listed in an acknowledgements section. Examples of those who might be acknowledged include a person who provided ... writing assistance.... Editors should ask corresponding authors to declare whether they had assistance with ...manuscript preparation. If such assistance was available, the authors should disclose the identity of the individuals who provided this assistance and the entity that supported it in the published article." 
The World Association of Medical Editors (WAME) recommends journal editors to modify their Instructions for Authors to mention that medical writers' contributions can be legitimate and should be mentioned in the acknowledgement section (16). Their role in the preparation of the manuscript and their affiliations should be clearly mentioned too. The Council of Science Editors (CSE) also encourages acknowledgement of any writing assistance (19).

The Committee on Publication Ethics (COPE) provides impartial advice to editors on cases they find difficult to resolve. It advises editors to encourage authors to acknowledge the contribution of professional writers and their funding source (20). COPE also guides editors on how to detect a contributor has not been adequately acknowledged.

The Good Publication Practice (GPP2) guidelines for communicating company sponsored medical research insist that all articles and presentations prepared with medical writing assistance should include an acknowledgement, "even if not requested by the journal or congress"(21). If the submission requirements do not allow the authors to include this information within the article or presentation, the GPP2 guidelines recommend inclusion of the information about writing assistance "in a letter that accompanies the submission". It encourages authors to use a published checklist to avoid ghostwriting $(21,22)$. This checklist has been developed by a group of medical writers (22). They hope that if journal editors ask authors to complete this checklist, it will discourage ghostwriting. In this checklist, authors are required to acknowledge professional medical writing assistance and its funding source, to confirm that the main points, outcomes and all data reported in the manuscript was controlled by the authors directly, and to verify that if needed the medical writers could prove that ethical writing guidelines were followed.

The European Association of Science Editors (EASE) has also published a checklist for authors of scientific manuscripts (23). The checklist requires authors to declare the contribution of medical writers in the acknowledgements. It is considered an obligatory declaration that applies to all manuscripts.
Many journals that adhere to the ICMJE, WAME, CSE, COPE and GPP2 guidelines or GATE principles encourage authors to declare medical writing assistance and state that ghostwriting is unacceptable.

\section{Ensuring a fair and appropriate acknowledgement of medical writers}

Some biomedical editors predict a gradual shift from the traditional authorship system to a model of contributorship (24). With a shift to the contributorship model, even medical writers who do not always qualify as authors will receive adequate acknowledgement for their contribution.

Stakeholders at each level need to ensure that there is total transparency about writing assistance and its funding (24). Research institutions that wish to publish honest articles should train their researchers on updated guidelines and policies in publication ethics. Authors must familiarize themselves with the journal's instructions to authors as more and more journals today encourage adequate acknowledgement of writing assistance. When reviewers suspect the involvement of a ghostwriter, they should report the same. Editors must ensure that the authors submit statement about contributorship. Publishers should make sure proper guidance is provided about authorship and acknowledgement in their instructions to authors.

It is the ethical responsibility of all the stakeholders of the medical publishing process to encourage transparency so that they can bring an end to the practice of ghostwriting. A medical writer who is not adequately acknowledged remains a ghostwriter.

\section{Potential conflict of interest}

Dr. Natasha Das reports receiving personal fees from medical writing, editing, training and revenues from a book on medical writing. She is also the Secretary of All India Medical Writers Association. This is not a paid position.

Dr. Saurendra Das reports being an Advisor to All India Medical Writers Association. This is not a paid position. 


\section{References}

1. McVeagh TC. Medical authors and professional writers. Calif Med 1963;99:104-5.

2. Woolley KL, Clemow D. Development and practical use of an international medical writer competency model. DIA Global Forum 2010;2:8-11.

3. Clemow DB. Pharmaceutical medical writing competency model. American Medical Writers Association Journal 2011;26:106-10.

4. Peh WC, Ng KH. Preparing a manuscript for submission. Singapore Med J 2009;50:759-61; quiz 762.

5. Rogers LF. Follow the yellow brick road: preparing a manuscript for submission to a scientific journal. AJR Am J Roentgenol 2002;179:1099-100. http://dx.doi.org/10.2214/ajr. 179.5.1791099.

6. Wyness $T$, McGhee C, Patel DV. Manuscript rejection in ophthalmology and visual science journals: identifying and avoiding the common pitfalls. Clin Experiment Ophthalmol 2009;37:864-7. http://dx.doi.org/10.1111/j.14429071.2009.02190.x.

7. Ohwovoriole AE. Writing Biomedical Manuscripts Part II: Standard Elements and Common Errors. West Afr J Med 2011;30:389-99.

8. Barron JP. The uniform requirements for manuscripts submitted to biomedical journals recommended by the International Committee of Medical Journal Editors. Chest 2006;129:1098-9. http://dx.doi.org/10.1378/chest.129.4. 1098.

9. Jacobs A, Wager E. European Medical Writers Association (EMWA) guidelines on the role of medical writers in developing peer-reviewed publications. Curr Med Res Opin 2005;21:317-22. http://dx.doi.org/10.1185/ $030079905 \times 25578$.

10. Daskalopoulou SS, Mikhailidis DP. The involvement of professional medical writers in medical publications. Curr Med Res Opin 2005;21:307-10. http://dx.doi.org/10.1185/ $030079905 \times 28944$.

11. Langdon-Neuner E. Medical ghost-writing. Mens Sana Monogr 2008;6:257-73. http://dx.doi.org/10.4103/0973-1229. 33006.

12. Wager E, Field EA, Grossman L. Good publication practice for pharmaceuticalcompanies. CurrMed Res Opin 2003;19:14954. http://dx.doi.org/10.1185/030079903125001767.

13. Laflin MT, Glover ED, McDermott RJ. Publication ethics: an examination of authorship practices. Am J Health Behav 2005;29:579-87. http://dx.doi.org/10.5993/AJHB.29.6.12.

14. Reider B. Ghostwriters and Guest-writers. The American Journal of Sports Medicine 2010;38:2183-5. http://dx.doi. org/10.1177/0363546510386548.
15. International Committee of Medical Journal Editors. Uniform Requirements for Manuscripts Submitted to Biomedical Journals: Ethical Considerations in the Conduct and Reporting of Research: Authorship and Contributorship. International Committee of Medical Journal Editors; 2013. Available at: http://www.icmje.org/ethical_1author.html. Accessed October 19, 2013.

16. World Association of Medical Editors Editorial Policy Committee. Policy Statements: Ghost Writing Initiated by Commercial Companies; updated June 20, 2005. Available at: http://www.wame.org/resources/policies\#ghost. Accessed October 19, 2013.

17. Woolley KL. Involvement of professional medical writers in manuscripts - A blessing or a curse? International Society of Managing and Technical Editors - Editorial Office News 2009:1-5.

18. Woolley KL, Lew RA, Stretton S, Ely JA, Bramich NJ, Keys JR, Monk JA, Woolley MJ. Lack of involvement of medical writers and the pharmaceutical industry in publications retracted for misconduct: a systematic, controlled, retrospective study. Curr Med Res Opin 2011;27:1175-82. http:// dx.doi.org/10.1185/03007995.2011.573546.

19. Council of Science Editors. CSE's White Paper on Promoting Integrity in Scientific Journal Publications; updated March 30, 2012. Available at: http://www.councilscienceeditors. org/i4a/pages/index.cfm?pageid=3638\#223. Accessed October 19, 2013.

20. Wager E. How to spot authorship problems. Available at: http://publicationethics.org/files/u7140/Authorship\%20 problems_0.pdf. Accessed January 8, 2014.

21. Graf C, Battisti WP, Bridges D, Bruce-Winkler V, Conaty $J M$, Ellison $J M$, et al. Research Methods \& Reporting. Good publication practice for communicating company sponsored medical research: the GPP2 guidelines. BMJ 2009;339:b4330. http://dx.doi.org/10.1136/bmj.b4330.

22. Gotzsche PC, Kassirer JP, Woolley KL, Wager E, Jacobs $A$, Gertel $A$, et al. What should be done to tackle ghostwriting in the medical literature? PLoS Med 2009;6:e23. http:// dx.doi.org/10.1371/journal.pmed.1000023.

23. European Association of Science Editors. EASE guidelines for authors and translators of scientific articles to be published in English. Ethics: European Association of Science Editors; 2013.

24. Gasparyan AY, Ayvazyan L, Kitas GD. Authorship problems in scholarly journals: considerations for authors, peer reviewers and editors. Rheumatol Int 2013;33:277-84. http:// dx.doi.org/10.1007/s00296-012-2582-2. 